\title{
EFEITO DOS NÍVEIS DE SUBSTITUIÇÃO DO FENO DE CAPIM-TIFTON 85 PELA CASCA DE MAMONA SOBRE O CONSUMO E DIGESTIBILIDADE DE NUTRIENTES POR CABRAS LEITEIRAS ${ }^{1}$
}

Sueli Freitas dos Santos ${ }^{2}$, Marco A. D. Bomfim ${ }^{3}$ Magno J. D.Cândido ${ }^{4}$. Lisa Presley S. Pereira $^{5}$, Liv S. Severino ${ }^{7}$, Jaime Miguel de Araújo Filho ${ }^{2}$

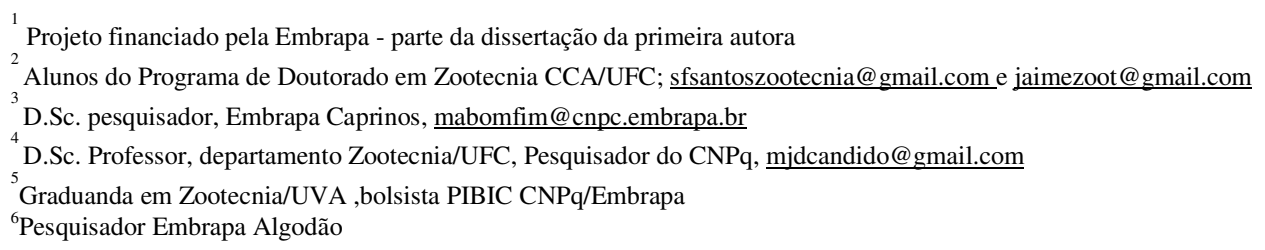

Resumo: Objetivou-se com o presente trabalho, avaliar o efeito dos níveis de substituição do feno de capim-tifton 85 sobre o consumo e digestibilidade de nutrientes em cabras leiteiras. Foram utilizadas oito fêmeas caprinas, da raça Anglo-Nubiana. Os animais foram alojados em gaiolas de metabolismo e distribuídos em um delineamento em quadrado latino 4 x 4 duplo. Os tratamentos consistiram de três níveis de substituição do feno de tifton pela casca de mamona como alimento volumoso $(0 ; 33 ; 67$ e 100\%), mantendo uma relação volumoso:concentrado de 50:50. Cada período experimental teve uma duração de 21 dias, sendo 14 dias de adaptação e sete dias de coleta de dados. A substituição do feno de capim-tifton 85 pela casca de mamona reduziu o consumo de todos os nutrientes: matéria seca, proteína bruta, extrato etéreo, fibra em detergente neutro, carboidrato não fibroso e carboidratos totais, Não houve diferença entre os coeficientes de digestibilidade. Portanto, o consumo de casca de mamona por estes animais pode ocorrer sem ocasionar grandes reduções no consumo e digestibilidade dos nutrientes.

Palavras-chave: coprodutos, dieta, fibra, nutrição de ruminantes, pequenos ruminantes

\section{EFFECT OF THE LEVELS OF SUBSTITUTION OF THE HAY OF GRASS-TIFTON 85 FOR CASTOR BEANS ON THE INTAKE AND DIGESTIBILITY OF NUTRIENTS FOR DAIRY GOATS}

Abstract: The experiment was assigned to evaluate the isubstituion of the castor bean hulls on intake and digestibility of nutrients for dairy goats of the goat's milk.t Nubian goat. The animals were distributed in metabolic cages, using an experimental design in double latin square $4 \times 4$. The treatments have consisted of three levels of substitution of the hay of bermudagrass for castor bean hulls as roughage $(0 ; 33 ; 67$ and 100\%), keeping a roughage:concentrate ratio of 50:50. Each experimental period had duration of 21 days, being 14 days of adaptation and seven days of collection of data. The substitution of castor bean hulls substituting the bermudagrass hay reduced the intake of nutrients: dry matter, crude protein, ether extract, neutral detergent fiber, non fiber carbohydrate and total carbohydrates. There were not difference enter the digestibility coefficients. Therefore, the consumption of castor oil plant peel for these animals can happen without causing great reductions in the intake and digestibility of the nutrients.

Keywords: byproduct, diets, fiber, ruminants nutrition, small ruminants

\section{Introdução}

A estacionalidade na produção de forragens verificada em determinadas épocas do ano tem sido responsável, dentre outros fatores, pela reduzida produtividade dos rebanhos. Uma forma de contornar esse problema é a adoção da prática do confinamento, ou do uso de alimentos alternativos. Entre as utilizações de fontes alternativas de alimentos, destaca-se a utilização de coprodutos a mamona. A utilização de coprodutos da mamona merece destaque, uma vez que essa cultura é adaptada a regiões semi-áridas, como a do nordeste brasileiro. O incentivo governamental para a produção de mamona destinada à extração do óleo deverá aumentar a quantidade de coprodutos desta cadeia produtiva, alguns deles com potencial para a utilização na alimentação animal. Dentre estes, está à casca de mamona. O presente estudo foi conduzido objetivando avaliar o efeito dos níveis de substituição do feno de capim-tifton 85 pela casca de mamona sobre o consumo e digestibilidade dos nutrientes por cabras leiteiras.

\section{Material e Métodos}


O experimento foi conduzido na Embrapa Caprinos em Sobral-CE. Foram utilizadas oito fêmeas caprinas leiteiras da raça anglo-nubiana. Os animais foram mantidos em gaiolas de metabolismo e distribuídos em um delineamento em quadrado latino 4 x 4 duplo. Para avaliar o efeito nutricional da casca de mamona em quatro níveis de substituição ao feno de capim-tifton 85, em dietas isoprotéicas e isoenergéticas, respeitando uma relação volumoso:concentrado de 50:50 em todos os tratamentos (Tabela 1). A casca de mamona, em função da participação de fragmentos de sementes, pode chegar a 13\% (Bomfim et al., 2006). A utilizada no experimento apresentava $6 \%$ de fragmentos de sementes, o que conferiu a este alimento fibroso $2,5 \%$ de extrato etéreo. Cada período experimental teve uma duração de 21 dias, sendo 14 dias de adaptação a dietas e sete dias de coleta de dados, totalizando 84 dias de período experimental. Os acessos às dietas, água e sal mineral foram ad libitum. $\mathrm{O}$ fornecimento das dietas foi dividido em duas refeições diárias, garantindo uma sobra entre $10 \%$ e $15 \%$ do total oferecido. Para estimativa do consumo e da digestibilidade dos nutrientes das dietas experimentais, no decorrer dos dias um a cinco de cada período experimental, foram efetuadas coletas dos alimentos e sobras, onde foram determinados os teores matéria seca (MS), proteína bruta (PB), extrato etéreo (EE), matéria mineral $(\mathrm{MM})$, fibra em detergente neutro (FDN), fibra em detergente ácido (FDA), celulose (CEL), lignina em ácido sulfúrico (LDA), nitrogênio insolúvel em detergente neutro (NIDN), nitrogênio insolúvel em detergente ácido (NIDA) e a concentração de nitrogênio na urina, segundo metodologias descritas em SILVA \& QUEIROZ (2002). O teor de carboidratos totais (CT) foi obtido pela fórmula: CT $=100$ (\% PB + \%EE +\%MM), conforme descrito em SNIFFEN et al.(1992). O teor de carboidratos não fibrosos (CNF) foi obtido pela diferença entre o teor de CT e o teor de FDN presentes as amostras, também seguindo metodologia descrita em SNIFFEN et al.(1992).Os dados foram analisados por meio de análise de regressão. A escolha do modelo baseou-se na significância dos coeficientes linear. A análise estatística dos dados foi feita com o auxílio do Software Sistema de Análises Estatísticas e Genéticas-SAEG (2007) e os efeitos dos tratamentos, avaliados ao nível de 0,05 de significância.

Tabela 1. Composição das dietas experimentais (base matéria seca)

\begin{tabular}{llllccccc}
\hline Dietas & MS (\%) & PB (\%) & EE (\%) & $\begin{array}{c}\text { FDN } \\
(\%)\end{array}$ & $\begin{array}{c}\text { EM } \\
(\mathrm{Mcal} / \mathrm{kg}\end{array}$ & $\mathrm{Ca}(\%)$ & $\mathrm{P}(\%)$ & $\begin{array}{c}\text { Relação } \\
\text { vol:conc }\end{array}$ \\
\hline $0 \%$ & 82,3 & 11,99 & 4,09 & 43,57 & 2,52 & 0,54 & 0,25 & $50: 50$ \\
$33 \%$ & 84,4 & 11,84 & 4,11 & 41,70 & 2,52 & 0,54 & 0,25 & $50: 50$ \\
$67 \%$ & 85,0 & 11,96 & 3,86 & 41,91 & 2,52 & 0,54 & 0,25 & $50: 50$ \\
$100 \%$ & 84,0 & 11,84 & 3,77 & 41,13 & 2,52 & 0,54 & 0,25 & $50: 50$ \\
\hline
\end{tabular}

\section{Resultados e Discussão}

O consumo de matéria seca em g/dia, \% PV e g/kgPV $\mathrm{kP}^{0,75}$ dos animais que receberam dietas com substituição de $67 \%$ de feno de capim-tifton 85 pela casca de mamona não foi diferente daqueles que receberam $100 \%$ de casca de mamona como fonte de volumoso. O mesmo foi observado para o CPB, CCNF e CCT. Para o CEE com 33, 67 e 100\% de substituição os resultados foram semelhantes. No entanto, o CFDN g/d foi diferente em todos os tratamentos, enquanto para o CFDN \%PV, as dietas 0 e $33 \%$ de substituição apresentaram semelhança, diferindo para os animais que receberam as dietas 67 e 100\% de substituição. Com o aumento no nível de substituição do feno de capim-tifton 85 pela casca de mamona, houve redução linear no consumo de matéria seca, expresso em g/dia, em \%PV/dia e em g/unidade de tamanho metabólico $\left(\mathrm{g} / \mathrm{kgPV}^{0,75}\right)$. Observa-se que níveis acima de $33 \%$ ocasionaram uma grande diminuição no consumo. Esta redução no consumo de matéria seca, por conseguinte, influenciou negativamente o consumo de todos os nutrientes avaliados (tabela 2 A redução do consumo de matéria seca pode ser atribuída a dois fatores: o primeiro está relacionado à qualidade da fibra. Apesar das dietas serem fibrosas, apresentando em sua composição cerca de 43,5\% do FDN total, a qualidade da fibra nos tratamentos provavelmente difere o que implica em possibilidade de alteração na efetividade física e ou química; o segundo relaciona-se com a palatabilidade e a digestibilidade das dietas, visto que, aumentando-se o nível de substituição, aumentava-se também a proporção de fragmentos de semente de mamona, na qual é constituída majoritariamente de um tipo de ácido graxo diferenciado (ricinoléico), que teve sua proporção 
aumentada com o aumento dos níveis de substituição. Não houve efeito dos tratamentos sobre os coeficientes de digestibilidade ( $\mathrm{P}>0,05)$ como mostra a tabela (Tabela 3 ). Relacionando os dados de consumo (Tabela 2) e digestibilidade (Tabela 3 ), verifica-se que a redução do consumo ocorre à medida que se aumenta os níveis de substituição de casca, o que não ocorreu com a digestibilidade. Possivelmente, isso ocorreu devido ao maior tempo de permanência do alimento consumido no rúmen, demonstrando que houve diferença na qualidade da fibra dos tratamentos como mencionado anteriormente.

Tabela 2. Consumo de matéria seca (CMS), de proteína bruta (CPB), de extrato etéreo (CEE), de fibra em detergente neutro (FDN), de carboidratos não fibrosos (CCNF) e de carboidratos totais (CCT) por cabras lactantes alimentadas com dietas contendo quatro níveis de substituição do feno de capim-tifton 85 pela casca de mamona

\begin{tabular}{|c|c|c|c|c|c|c|c|}
\hline \multirow{2}{*}{ Variáveis } & \multicolumn{4}{|c|}{ Níveis de casca } & \multirow{2}{*}{ Equação estimada $^{a}$} & \multirow[t]{2}{*}{$\mathbf{R}^{2}$} & \multirow{2}{*}{$\begin{array}{l}\mathbf{C V}^{\mathbf{b}} \\
(\%)\end{array}$} \\
\hline & $\mathbf{0 \%}$ & $33 \%$ & $67 \%$ & $100 \%$ & & & \\
\hline CMS (g/d) & $1702,03 a$ & $1437,70 \mathrm{~b}$ & $1085,70 \mathrm{c}$ & $1024,14 \mathrm{c}$ & $\hat{\mathrm{Y}}=1908,80-238,5^{* *} \mathrm{x}$ & 0,74 & 9,89 \\
\hline CMS (\%PV) & $3,85 \mathrm{a}$ & $3,40 \mathrm{~b}$ & $2,62 \mathrm{c}$ & $2,54 \mathrm{c}$ & $\hat{\mathrm{Y}}=4,26-0,467^{* *} \mathrm{x}$ & 0,45 & 9,28 \\
\hline CMS (g/kgPV $\left.{ }^{0,75}\right)$ & $99,21 \mathrm{a}$ & $85,80 \mathrm{~b}$ & $66,44 \mathrm{c}$ & $63,88 \mathrm{c}$ & $\hat{\mathrm{Y}}=110,16-12,53^{* *} \mathrm{x}$ & 0,57 & 9,24 \\
\hline $\mathrm{CPB}(\mathrm{g} / \mathrm{d})$ & $213,40 \mathrm{a}$ & $181,90 \mathrm{~b}$ & $145,08 \mathrm{c}$ & $145,10 \mathrm{c}$ & $\hat{Y}=232,79-24,77^{* *} x^{* *}$ & 0,68 & 9,91 \\
\hline $\mathrm{CEE}(\mathrm{g} / \mathrm{d})$ & $74,30 \mathrm{a}$ & $63,70 \mathrm{~b}$ & $46,67 b$ & $45,10 \mathrm{~b}$ & $\hat{\mathrm{Y}}=83,12-10,19^{* *} \mathrm{x}^{* *}$ & 0,74 & 9,69 \\
\hline CFDN (g/d) & $672,00 \mathrm{a}$ & $536,60 \mathrm{~b}$ & $400,90 \mathrm{c}$ & $301,52 d$ & $\hat{Y}=789,54-124,71^{* *} x$ & 0,78 & 11,43 \\
\hline CFDN (\%PV) & $1,52 \mathrm{a}$ & $1,25 \mathrm{a}$ & $0,95 b$ & $0,74 \mathrm{~b}$ & $\hat{\mathrm{Y}}=1,77-0,261^{*} \mathrm{x}$ & 0,64 & 13,42 \\
\hline $\mathrm{CCNF}(\mathrm{g} / \mathrm{d})$ & $709,51 \mathrm{a}$ & $618,50 \mathrm{~b}$ & $483,35 \mathrm{c}$ & $497,01 \mathrm{c}$ & $\hat{\mathrm{Y}}=770,25-77,26^{* *} \mathrm{x}$ & 0,65 & 9,59 \\
\hline $\mathrm{CCT}(\mathrm{g} / \mathrm{d})$ & $1381,51 \mathrm{a}$ & $1155,10 \mathrm{~b}$ & $860,80 \mathrm{c}$ & $798,53 d$ & $\hat{Y}=1559,80-204,32^{* *} x$ & 0,76 & 9,98 \\
\hline
\end{tabular}

Tabela 3. Digestibilidade da matéria seca (DMS), da proteína bruta (DPB), do extrato etéreo (DEE), da fibra em detergente neutro (DDN), dos carboidratos totais (DCT) e dos carboidratos não fibrosos (DCNF) por cabras lactantes alimentadas com dietas contendo quatro níveis de substituição do feno de capim-tifton 85 pela casca de mamona

\begin{tabular}{lccccc}
\hline \multirow{2}{*}{ Variáveis } & \multicolumn{4}{c}{ Níveis de casca } & \multirow{2}{*}{ Significância } \\
\cline { 2 - 5 } & $\mathbf{0 \%}$ & $\mathbf{3 3 \%}$ & $\mathbf{6 7 \%}$ & $\mathbf{1 0 0 \%}$ & \\
\hline DMS (\%) & 77,92 & 71,70 & 74,40 & 79,49 & $\mathrm{~ns}$ \\
DPB (\%) & 76,20 & 70,02 & 72,98 & 79,51 & $\mathrm{~ns}$ \\
DEE (\%) & 84,18 & 81,98 & 84,81 & 89,68 & $\mathrm{~ns}$ \\
DFDN (\%) & 65,26 & 52,44 & 60,66 & 57,14 & $\mathrm{~ns}$ \\
DCT (\%) & 80,34 & 74,47 & 78,18 & 81,09 & $\mathrm{~ns}$ \\
DCNF (\%) & 94,30 & 93,51 & 93,38 & 95,28 & $\mathrm{~ns}$ \\
\hline \multicolumn{7}{l}{ ns (não significativo; $(P>0,05))$} & & & &
\end{tabular}

\section{Conclusões}

Conclui-se que, a casca de mamona pode ser utilizada na dieta de cabras leiteiras como alimento volumoso alternativo, sem ocasionar grandes reduções no consumo e digestibilidade dos nutrientes.

\section{Literatura citada}

BOMFIM, M.A.D.; SEVERINO, L. S.; CAVALCANTE, A. C. R. et al. Avaliação da casca de mamona na alimentação animal de ovinos. In: congresso nordestino de produção animal, 4, Petrolina, 2006. Anais... Petrolina: Sociedade Nordestina de Produção Animal; Embrapa SemiÁrido, 2006 (CD-ROM).

SILVA, D.J.; QUEIROZ, A.C. Análise de alimentos (métodos químicos e biológicos). 3. ed. Viçosa, MG: Universidade Federal de Viçosa, 2002. 235p.

SNIFFEN, C.J., O'CONNOR, J.D., VAN SOEST, P.J. et al. A net carbohydrate and protein system for evaluating cattle diets. II. Carbohydrate and protein availability. Journal of Animal Science, v.70, p. 3562-3577, 1992.

SAEG - Sistema para Análises Estatísticas e Genéticas, versão 9.1: Fundação Arthur Bernardes - UFV - Viçosa, 2007. 